\title{
Work-family conflict as a predictor of common mental disorders in the 1958 British birth cohort
}

\author{
Tahera Razavi Department of Psychology, School of Biological and Chemical Sciences, Queen Mary, \\ University of London, UK \\ Charlotte Clark Centre for Psychiatry, Wolfson Institute of Preventive Medicine, Barts \& The London \\ School of Medicine \& Dentistry, Queen Mary University of London, UK \\ Stephen A Stansfeld Centre for Psychiatry, Wolfson Institute of Preventive Medicine, Barts \& The London \\ School of Medicine \& Dentistry, Queen Mary University of London, UK \\ s.a.stansfeld@qmul.ac.uk
}

(Received November 2014

Revised May 2015)

http://dx.doi.org/10.14301/Ilcs.v6i3.327

\section{Abstract}

The impact of work-family conflict on common mental disorders (CMD) has been examined in cross-sectional studies. The current paper examines work-family conflict and its effect on CMD in a large nationally representative longitudinal sample. This study uses data from the 1958 British birth cohort study, a longitudinal, prospective cohort study of men and women born in a single week in 1958. At 45 years 9,297 individuals were followed up and 9,008 individuals were working. In this sample work-family conflict, sociodemographic factors and the number of hours worked were assessed at age 42 years. The Revised Clinical Interview Schedule (CIS-R) was used to assess CMD, as classified by the International Statistical Classification of Diseases, $10^{\text {th }}$ Revision (ICD-10), in cohort members at age 45 years. Work-family conflict was prospectively associated with an increased risk of common mental disorders (OR=1.76 95\% Cl 1.36-2.20) adjusting for gender, marital status, social class and educational qualifications. However there was no significant prospective association between the number of hours worked and the prevalence of CMD in this cohort. These results suggest that work-family conflict is a risk factor for future common mental disorder and that in order to prevent common mental disorder this should be considered in job planning. There is a need for more prospective studies with more detailed measures of workfamily conflict to confirm these results.

Keywords: work; work family conflict; working hours; mental health; cohort studies; depression; longitudinal studies

\section{Introduction}

The balance between paid work and the life outside work has become an important focus in Britain (Lewis, 2003; Taylor, 2002; Wheatley, 2012). This issue has arisen due to the increase in nontraditional, dual-career households and singleparent households who do not confine work and life commitments to traditional gender roles (Byron, 2005).

The complex balance between work and life requires developing equilibrium between both activities and roles outside work or leisure activities and paid employment (Guest, 2002; Lowry \& Moskos, 2008). The interference between the fulfilment of each of these roles is considered to 
generate work-life conflict (Reynolds, 2005). This conflict is considered to have direction, signifying that work activities can impact on life activities and vice versa - in this direction it is often termed family-work conflict (Greenhaus \& Parasuraman, 1999; Frone, Russell, \& Cooper, 1992).

Work and family life can both influence the prevalence of mental health conditions. Work-life conflict and family-work conflict have been crosssectionally associated with mood, anxiety and substance use disorders (Frone, 2000; Grzywacz \& Bass, 2003; Seto, Morimoto, \& Maruyama, 2004; Wang, Lesage, Schmitz, \& Drapeau, 2006; Obidoa, Reeves, Warren, Reisine, \& Cherniack, 2011; Nitzche, Jung, Pfaff, \& Driller, 2012). These studies suggest that work-life imbalance can be considered to be an aspect of the multifactorial aetiology of common mental disorders (Kendler, Prescott, Myers, \& Neale, 2003; Hämmig \& Bauer, 2009). Common mental disorders, most frequently, depressive and anxiety disorders are the mental health conditions most likely to arise from psychosocial stressors.

Several structural factors may influence work-life balance such as gender, marital status and socioeconomic status (Barnett \& Hyde, 2001; Cinamon \& Rich, 2002; Duxbury, Higgins \& Lee, 1994). It may be more difficult for women to attain a balance between work and life, because they often take the largest share of domestic duties and childcare (Frone, 2000; Canivet et al., 2010). However Byron (2005) found that gender alone was a poor predictor of work-family conflict. Widowed and divorced males and females have higher incidence rates of mental disorders compared to single and married males and females (Bebbington, 1987). Duxbury, Higgins and Lee (1994) found that single parents faced similar work-family conflict as those who were married. Similarly, Byron (2005) concluded that marital status was not a good predictor of work-family conflict.

Socioeconomic status is often associated with poor health (Adler \& Ostrove, 1999; Hemingway, Nicholson, Stafford, Roberts, \& Marmot, 1997). Lorant et al., (2003) found that individuals in the lowest socioeconomic group were 2.5 times more likely to have depressive disorder than those in the highest socioeconomic group. Clark et al., (2011) suggest that financial crises such as being in debt are associated with prevalence of common mental disorders (CMD). Social disadvantage may mean that people are unable to afford the resources that could buffer the strain involved in carrying out work and non-work roles simultaneously.

Time balance and allocation is also considered to influence the difficulties faced in attaining stability between work and life outside work. Spurgeon, Harrington \& Cooper (1997) concluded that long working hours, specifically working hours greater than fifty hours per week were associated with risks to mental health. Virtanen et al., (2011) found that there was a significantly greater risk of depressive and anxiety symptoms among those working over fifty-five hours per week as compared to those working between thirty-five to forty hours per week. Part of this increased risk may be due to working irregular hours as working rotating shifts and having irregular, changing hours has been related to greater risk of common mental disorders than working regular schedules (Martens, Nijhuis, Van Boxtel, \& Knottnerus, 1999).

However, although the impact of life activities on work activities and vice versa may conflict with one another they can also have a positive or complementary effect on each other (Greenhaus \& Parasuraman, 1999). Equally Lewis (2003) advocates that people may enjoy working and gain a sense of satisfaction from it, and suggests that there are individual differences in the balance between work and life.

In summary, the aforementioned studies suggest that there is an association between work-life conflict and prevalence of mental ill health. However as these findings rely upon cross-sectional methodology they are insufficient as evidence to assess causal relationships (Casper, Eby, Bordeaux, Lockwood, \& Lambert, 2007; Hämmig, Gutzwiller\& Bauer, 2009).

Also, prior research regarding work-life conflict has often limited the research population to specific categories or professions (Hämmig et al., 2009) and many studies are not nationally representative as they are limited to subpopulations (Seto et al., 2004; Shimazu, Bakker, Demerouti \& Peeters, 2010; Takeuchi \& Yamazaki, 2010; Janzen \& Kelly, 2012; Grant-Vallone \& Ensher, 2001).

In the present study, we use a nationally representative sample, the 1958 British birth cohort of people born in England, Scotland and Wales in one week in 1958 to examine the association of work-family conflict and working hours on common mental disorders. 
The aims of this study are:

1. To assess whether work-life conflict is associated with common mental disorders three years later.

2. To assess whether the number of hours worked is associated with common mental disorders three years later.

A relatively short three year follow up allows for immediate effects of work-life conflict expected on common mental disorders to be captured and is brief enough for work and family responsibilities not to have changed much in the interval.

\section{Method}

\section{Sample}

The 1958 British birth cohort originated as a study into perinatal mortality assessing over 17,000 births in England, Wales and Scotland, in a single week in March 1958. Data were attained on 17,414 (98.2\%) of the birth of the total 17,733 births in the first survey (Parsons, Power, \& Manor, 2001). Nine further followup surveys have been conducted when the cohort members were aged seven, 11, 16, 23, 33, 42, 45, 50 and 55 years (Power \& Elliott, 2006) collecting data from parents, medical examinations and records, school, and from the cohort members. The South East Multi-Centre Research Ethics Committee provided ethical approval for the survey. These analyses utilise data from the 42 year and 45 year surveys.

\section{Measures}

\section{Sociodemographic Factors}

Cohort members' marital status was assessed at the 42-year survey and classified as single, married, separated, divorced or widowed. Registrar General social class was assessed at the 42-year survey, classified as social class I or II, III non-manual, III manual, IV or V (Power \& Elliott, 2006). Cohort members self-reported their educational qualification level as "none", "O-levels" and "A-levels or higher".

\section{Work-family conflict and working hours}

Current main activity was defined through whether cohort members were self-employed, not working, part-time paid employees or full-time paid employees. This paper focuses on cohort members who were fulltime or part-time paid employees.

Cohort members were given a questionnaire regarding psychosocial work characteristics at 42 years. Work-family conflict was assessed by a selfreport question about job demands. Cohort members were asked to answer the question "Do you think the demands of your work interfere with the demands of home and family life?" with either "yes" or "no". The emotional demands of the cohort member's job were reported by the question "How mentally/emotionally demanding is work?". In response, cohort members were asked to state "a lot", "a moderate amount" or "very little". Hours worked per week were selfreported, and excluded time for meal breaks and overtime.

\section{Common Mental Disorders}

Common mental disorders were assessed during the 45 -year follow-up by the revised Clinical Interview Schedule (CIS-R) (Lewis, Pelosi, Araya, \& Dunn, 1992) administered by a nurse using a computer-assisted personal interview conducted in the cohort members home (Stansfeld, Clark, Rodgers, Caldwell, \& Power, 2008). Disorders were assessed in the preceding week according to the International Statistical Classification of Diseases, $10^{\text {th }}$ Revision (ICD-10), which allowed the classification of common mental disorders.

Diagnoses included were depressive episodes, classified as mild, moderate or severe, generalised anxiety disorder (GAD), phobias (agoraphobia and social phobia) and panic disorder (Clark, Rodgers, Caldwell, Power, \& Stansfeld, 2007). It was also possible to have a co-morbid diagnosis of the aforementioned conditions. A dichotomous outcome, 'any diagnosis' was based on the presence or absence of any of these diagnoses.

\section{Statistical Analyses}

Analyses were performed using SPSS Version 18.0 (SPSS Inc., USA). In order to assess the longitudinal association of work-family conflict, working hours and socioeconomic factors on common mental disorders, binary logistic regression analyses were used.

Initially the prevalence of common mental disorders was established and co-occurrence was assessed through the use of chi-square tests between the diagnosis of common mental disorders and workfamily conflict, working hours, and socioeconomic factors. Logistic regression analyses predicting the relationship of work-family conflict and hours worked per week on CMD were conducted, initially unadjusted, and then adjusted for gender, social class and marital status. All estimates were expressed as odds ratios with $95 \%$ confidence intervals in relation to the reference group.

The associations of marital status, social class and gender on work-family conflict were initially explored through chi-square tests, followed by regression 
analyses on work-family conflict and marital status, social class and gender in the 42 year sample. Regression analyses were also conducted on workfamily conflict and work hours both with and without overtime. These were also expressed as odds ratios with $95 \%$ confidence intervals in relation to the reference group.

\section{Results}

\section{Descriptives of the sample}

Of the original 18,558 cohort members, 11,419 cohort members completed the 42-year follow up and 9,297 cohort members completed the 45-year biomedical survey, of whom 562 (6\%) had a diagnosis of at least one CMD. Of the working sample of 9,008 individuals, $50 \%$ were female, $72 \%$ were married, $57 \%$ were employed full time and $35 \%$ were of manual social class.

Prevalence of sociodemographic factors, workfamily conflict and working hours and unadjusted odds for common mental disorder

Table 1 shows the odds of common mental disorders (CMD) associated with sociodemographic factors. Being single was associated with a $52 \%$ increase in odds for a CMD compared to being married or remarried. Furthermore, being divorced, separated or widowed was associated with almost double the odds of a CMD. Females had a 55\% increase in odds for a CMD.

Social class was also associated with increased odds for CMD; social classes IV and V had a 52\% increase in odds compared with classes I and II. However, social class III non-manual and social class III manual did not have increased odds compared with classes I and II. Being educated up to O-level qualifications was associated with a $26 \%$ increase in odds for a CMD compared to having A-levels or higher: those with no qualifications had almost a three-fold increase in odds for a CMD.

Those who were employed part-time had significantly higher odds of a CMD compared with those employed full-time. Those who were unemployed had a three-fold increase in odds for a CMD compared with those employed full-time. In the working sample of 9,008 individuals, those who experienced work-family conflict had a $38 \%$ increase in odds for CMD, however mental and emotional demands of work were not significantly associated with CMD. In this sample neither the number of hours worked, not including overtime, nor the amount of overtime worked were found to be associated with CMD. 
Table 1. Unadjusted odds ratio ( $95 \%$ confidence interval) for diagnosis of common mental disorders at $\mathbf{4 5}$ years by sociodemographic factors at $\mathbf{4 2}$ years

\begin{tabular}{|c|c|c|c|c|}
\hline & N (\%) & OR & $95 \% \mathrm{C}$ & \\
\hline Married/remarried & 6481 (71.9) & 1.00 & & \\
\hline Single & $1085(12.0)$ & $1.52 *$ & 1.18 & 1.95 \\
\hline Divorced/separated/widowed & $1442(16.0)$ & $1.82 *$ & 1.47 & 2.25 \\
\hline Gender & 9297 & & & \\
\hline Male & $4622(49.7)$ & 1.00 & & \\
\hline Female & $4675(50.3)$ & $1.55^{*}$ & 1.31 & 1.85 \\
\hline Social class at 42 year & 7752 & & & \\
\hline I and II & $3422(44.1)$ & 1.00 & & \\
\hline III non-manual & $1645(21.2)$ & 1.27 & 0.97 & 1.67 \\
\hline III manual & $1529(19.7)$ & 0.94 & 0.70 & 1.28 \\
\hline IV and V & $1156(14.9)$ & $1.52^{* *}$ & 1.14 & 2.03 \\
\hline Educational qualifications & 8087 & & & \\
\hline A-levels or higher & $3843(47.5)$ & 1.00 & & \\
\hline O-levels & $3622(44.8)$ & 1.26 & 1.03 & 1.54 \\
\hline None & $622(7.7)$ & $2.73^{*}$ & 2.06 & 3.63 \\
\hline Employment status & 9008 & & & \\
\hline Full-time & $5115(56.8)$ & 1.00 & & \\
\hline Part-time & 1525 (16.9) & 1.42 & 1.11 & 1.81 \\
\hline Not working & $1227(13.6)$ & $3.22 * * *$ & 2.61 & 3.98 \\
\hline Self employed & $1141(12.7)$ & 0.98 & 0.72 & 1.34 \\
\hline Does work interfere with family life? & 7777 & & & \\
\hline No & $3600(46.3)$ & 1.00 & & \\
\hline Yes & $4177(53.7)$ & $1.38^{* *}$ & 1.12 & 1.71 \\
\hline How mentally/emotionally demanding is work? & 7779 & & & \\
\hline Very little & $935(12.0)$ & 1.00 & & \\
\hline Moderate amount & $2542(32.7)$ & 0.74 & 0.51 & 1.08 \\
\hline A lot & $4302(55.3)$ & 1.20 & 0.86 & 1.66 \\
\hline
\end{tabular}




\begin{tabular}{|c|c|c|c|c|}
\hline Any children aged $0-16 ?$ & 8998 & & & \\
\hline Yes & $6193(68.8)$ & 1.00 & & \\
\hline No & $2805(31.2)$ & $1.38 * * *$ & 1.15 & 1.65 \\
\hline How long does it take to travel to work? & 7304 & & & \\
\hline 0-30 minutes & $5134(70.3)$ & 1.00 & & \\
\hline 30 minutes- 1 hour & $1410(19.3)$ & 0.95 & 0.72 & 1.26 \\
\hline Over 1 hour & $500(6.8)$ & 1.26 & 0.85 & 1.86 \\
\hline Works at home & $260(3.6)$ & 1.04 & 0.59 & 1.84 \\
\hline $\begin{array}{l}\text { Total hours worked per week for those that do } \\
\text { not work overtime and for those that do work } \\
\text { overtime }\end{array}$ & 6291 & 0.99 & 0.98 & 1.00 \\
\hline $\begin{array}{l}\text { Usual hours worked per week for those that do } \\
\text { not work overtime }\end{array}$ & $\begin{array}{l}2608 \\
1484(56.9)\end{array}$ & 1.00 & & \\
\hline $31-50$ hours & $180(6.9)$ & 0.43 & 0.16 & 1.20 \\
\hline $\begin{array}{l}\text { Over } 51 \text { hours } \\
\text { Less than } 31 \text { hours }\end{array}$ & $944(36.2)$ & 1.09 & 0.75 & 1.57 \\
\hline $\begin{array}{l}\text { Usual hours worked per week including paid } \\
\text { and unpaid overtime }\end{array}$ & 3683 & 0.99 & 0.98 & 1.00 \\
\hline Total hours worked excluding overtime & 6581 & 0.99 & 0.98 & 1.00 \\
\hline Any overtime worked, paid and unpaid? & 6297 & & & \\
\hline No overtime & $2864(45.5)$ & 1.00 & & \\
\hline $1-10$ hours & $2534(40.2)$ & 0.96 & 0.75 & 1.23 \\
\hline Over 11 hours & $899(14.3)$ & 0.95 & 0.67 & 1.35 \\
\hline
\end{tabular}

$* * * \mathrm{p} \leq .001$

$* * \mathrm{p} \leq .01$

$* p \leq .05$

In the working sample at 42 years, work-family conflict was greater in women, single, separated, divorced and widowed people, those of manual social class, part time workers and those without children (table 2). Those who had a travel time to work of over thirty minutes did not experience significantly more work-family conflict. However, those who worked less than thirty-one hours had a two-fold increase of work-family conflict in comparison with those who worked the norm of 3150 hours, whereas those who worked over 51 hours had a decreased odds of work-family conflict. Correspondingly those who worked overtime were significantly less likely to experience work-family conflict than those who did not work overtime 
Table 2. Unadjusted odds ratio ( $95 \%$ confidence interval) for work-family conflict by sociodemographic factors at $\mathbf{4 2}$ years

\begin{tabular}{|c|c|c|c|c|}
\hline & N (\%) & OR & $95 \% \mathrm{C}$ & \\
\hline Married/remarried & $6988(72.7)$ & 1.00 & & \\
\hline Single & 1144 (11.9) & $1.32 * * *$ & 1.17 & 1.50 \\
\hline Divorced/separated/widowed & $1482(15.4)$ & $1.26 * * *$ & 1.13 & 1.42 \\
\hline Gender & 9616 & & & \\
\hline Male & $4549(47.3)$ & 1.00 & & \\
\hline Female & $5067(52.7)$ & $2.01 * * *$ & 1.85 & 2.18 \\
\hline Social class at 42 years & 9581 & & & \\
\hline I and II & $4112(42.9)$ & 1.00 & & \\
\hline III non-manual & $2043(21.3)$ & $3.01 * * *$ & 2.70 & 3.36 \\
\hline III manual & $1937(20.2)$ & $1.90 * * *$ & 1.70 & 2.12 \\
\hline IV and V & $1489(15.5)$ & $4.03 * * *$ & 3.56 & 4.57 \\
\hline Employment status & 9616 & & & \\
\hline Full-time & $6323(65.8)$ & 1.00 & & \\
\hline Part-time & $1876(19.5)$ & $3.27^{* * *}$ & 2.92 & 3.65 \\
\hline Self employed & $1417(14.7)$ & 0.98 & 0.87 & 1.10 \\
\hline Any children aged $0-16 ?$ & 9606 & & & \\
\hline Yes & $6499(67.7)$ & 1.00 & & \\
\hline No & $3107(32.3)$ & $1.59 * * *$ & 1.25 & 1.74 \\
\hline How long does it take to travel to work? & 9028 & & & \\
\hline $0-30$ minutes & $6337(70.2)$ & 1.00 & & \\
\hline 30 minutes- 1 hour & $1748(19.4)$ & $0.62 * * *$ & 0.56 & 0.69 \\
\hline Over 1 hour & $611(6.8)$ & $0.43^{* * *}$ & 0.36 & 0.52 \\
\hline Works at home & $332(3.7)$ & 0.85 & 0.68 & 1.06 \\
\hline $\begin{array}{l}\text { Total hours worked per week for those that do } \\
\text { not work overtime and for those that do work } \\
\text { overtime }\end{array}$ & 7746 & $0.94 * * *$ & 0.94 & 0.95 \\
\hline $\begin{array}{l}\text { Usual hours worked per week for those that do } \\
\text { not work overtime }\end{array}$ & 3265 & & & \\
\hline $31-50$ hours & $1837(56.3)$ & 1.00 & & \\
\hline Over 51 hours & $231(7.1)$ & $0.17^{* * *}$ & 0.12 & 0.24 \\
\hline Less than 31 hours & $1197(36.7)$ & $2.23 * * *$ & 1.90 & 2.62 \\
\hline
\end{tabular}




\begin{tabular}{lllll}
\hline $\begin{array}{l}\text { Usual hours worked per week including paid } \\
\text { and unpaid overtime }\end{array}$ & 4481 & $0.95^{* * *}$ & 0.94 & 0.95 \\
\hline Total hours worked excluding overtime & 8120 & $0.95^{* * *}$ & 0.94 & 0.95 \\
\hline Any overtime worked, paid and unpaid? & 7752 & & & \\
No overtime & $3576(46.1)$ & 1.00 & & \\
$1-10$ hours & $3056(39.4)$ & $0.56^{* * *}$ & 0.50 & 0.61 \\
Over 11 hours & $1120(14.4)$ & $0.19^{* * *}$ & 0.16 & 0.22 \\
\hline \hline
\end{tabular}

$* * * p \leq .001$

$* * p \leq .01$

Adjusted analyses of work-family conflict and

\section{CMD}

Table 3 shows the associations between workfamily conflict, working hours and CMD at 45 years adjusted for social class, gender, marital status and educational qualifications. After adjustment, the odds of work-family conflict for CMD three years later increased and the odds for mental and emotional demands of work also increased and became statistically significant. Upon adjustment, work hours and overtime were not significantly associated with CMD.

Table 3. Adjusted odds ratio ( $95 \%$ confidence interval) for diagnosis of common mental disorders at $\mathbf{4 5}$ years by sociodemographic factors at $\mathbf{4 2}$ years

\begin{tabular}{lllll}
\hline \hline \multicolumn{1}{l}{ Adjusted for social class, gender, marital status and qualifications } & & & \\
\hline & $\mathrm{N}$ & $\mathrm{OR}$ & $95 \% \mathrm{Cl}$ & \\
\hline Employment status & 6829 & & & \\
Full-time & $4456(65.3)$ & 1.00 & & \\
Part-time & $1382(20.2)$ & 1.17 & 0.86 & 1.59 \\
Self employed & $991(14.5)$ & 0.87 & 0.61 & 1.24 \\
\hline Does work interfere with family life? & 6827 & & & \\
No & $3147(46.1)$ & 1.00 & & \\
Yes & $3680(53.9)$ & $1.73^{* * *}$ & 1.36 & 2.20 \\
& & & & \\
\hline How mentally/emotionally demanding is work? & 6828 & & & \\
Very little & $804(11.8)$ & 1.00 & & \\
Moderate amount & $2240(32.8)$ & 0.92 & 0.60 & 1.39 \\
A lot & $3784(55.4)$ & $1.72^{* *}$ & 1.17 & 2.54 \\
\hline
\end{tabular}




\begin{tabular}{|c|c|c|c|c|}
\hline View on security of current job & 6811 & & & \\
\hline Very secure & $2419(35.5)$ & 1.00 & & \\
\hline Fairly secure & $3642(53.5)$ & 1.19 & 0.93 & 1.52 \\
\hline Not very secure & $750(11.0)$ & 1.32 & 0.91 & 1.91 \\
\hline Any children aged $0-16 ?$ & 6825 & & & \\
\hline Yes & 4769 (69.9) & 1.00 & & \\
\hline No & $2056(30.1)$ & 1.15 & 0.89 & 1.48 \\
\hline How long does it take to travel to work? & 6423 & & & \\
\hline 0-30 minutes & $4514(70.3)$ & 1.00 & & \\
\hline 30 minutes- 1 hour & $1243(19.4)$ & 1.08 & 0.80 & 1.47 \\
\hline Over 1 hour & $432(6.7)$ & $1.56^{*}$ & 1.02 & 2.39 \\
\hline Works at home & $234(3.6)$ & 1.09 & 0.58 & 2.03 \\
\hline $\begin{array}{l}\text { Total hours worked per week for those that do } \\
\text { not work overtime and for those that do work } \\
\text { overtime }\end{array}$ & 5529 & 1.00 & 0.99 & 1.01 \\
\hline
\end{tabular}

\begin{tabular}{lllll}
\hline $\begin{array}{l}\text { Usual hours worked per week for those that do } \\
\text { not work overtime }\end{array}$ & 2273 & & & \\
31-50 hours & $1281(56.4)$ & 1.00 & & \\
$\begin{array}{l}\text { Over } 51 \text { hours } \\
\text { Less than } 31 \text { hours }\end{array}$ & $152(6.7)$ & 0.58 & 0.20 & 1.66 \\
\hline $\begin{array}{l}\text { Usual hours worked per week including paid } \\
\text { and unpaid overtime }\end{array}$ & 3256 & 1.00 & 0.98 & 1.01 \\
\hline Total hours worked excluding overtime & 5785 & 1.00 & 0.99 & 1.01 \\
\hline $\begin{array}{l}\text { Any overtime worked, paid and unpaid? } \\
\text { No overtime }\end{array}$ & 2534 & & & \\
1-10 hours & $2252(40.7)$ & 1.13 & 0.87 & 1.49 \\
Over 11 hours & $789(14.3)$ & 1.27 & 0.86 & 1.88 \\
\hline \hline
\end{tabular}

$* * * \mathrm{p} \leq .001$

$* * \mathrm{p} \leq .01$

$* p \leq .05$ 


\section{Discussion}

In these analyses of the 1958 birth cohort we found that work-family conflict was predictive of common mental disorders, whereas the amount of hours spent at work did not increase the risk of CMD three years later. The analyses are longitudinal and the associations regarding work-family conflict persist after adjustment for marital status, social class, gender and educational qualifications.

Work-family conflict was more frequent in women, those who were single, widowed, divorced or separated, those of less advantaged social class and those working part-time (<31 hours per week).

\section{Implications}

\section{Work-family conflict and mental health}

In previous cross-sectional studies (Wang et al., 2006; Frone, 2000) work-family conflict was associated with the prevalence of CMD. The current study demonstrates that work-family conflict is a significant risk indicator for $\mathrm{CMD}$ and a contributor to the complex aetiology of CMD (Kendler et al., 2003). The longitudinal methodology in the current paper adds to the evidence that the association of work-family conflict and the prevalence of $\mathrm{CMD}$ may be causal.

\section{Work-family conflict and family structure}

Despite the social transformations regarding male and female roles in society (Simon, 2002) women had almost twice the odds of work-family conflict compared with men. This was in accordance with Duxbury, Higgins and Lee (1994) who found that women had higher levels of conflict between work and family than men. Equally a potential explanation for the findings may be due to non-traditional roles for males and females. For women, family roles have been traditionally considered to be the core role and paid employment considered to be the nontraditional role. Therefore those women who work may face increased anxiety due to their opinion on their adequacy of fulfilling traditional family roles such as partner or parent (Duxbury \& Higgins, 1991).

In contrast to Duxbury, Higgins and Lee (1994), those who were single, divorced, separated and widowed were more likely to experience work-family conflict than those who were married. This may be due to factors such as household duties and domestic help associated with children, as those who are married may share those responsibilities (Bedeian, Burke and Moffett, 1988). Equally it may be due to other factors such as spouse support moderating the effects of work- family conflict (Fu \& Shaffer, 2001). It may be the case that residing with a partner is a more relevant signifier than marital status and thus the unexplained finding of higher work-family conflict in 'single' respondents may still reflect the presence of co-habiting partners. Social class had a prominent impact on work-family conflict as social classes III non-manual and manual, IV and V had an increased risk of CMD compared to those who were in social classes I and II. This may be due to a lack of resources to cope with both work and nonwork roles and feeling financially insecure (SinghManoux, Adler \& Marmot, 2003).

\section{Work-family conflict and working hours}

There was a significant three-fold risk of workfamily conflict for those who work part-time as compared to those who work full-time. This may be because part-time work entails irregular hours, which may interrupt family routines (Wheatley, 2012). Equally it may be due to a potential difference in income between those who work full-time and those who work part-time as financial issues are often a cause for concern in relation to CMD (Clark et al., 2011). Part-time work may also be chosen if there are other potentially stressful roles such as caring which may contribute both to increased work-family conflict and increased CMD risk. By contrast, the ability to work overtime may also be possible only if you have fewer commitments outside work.

We did not find a significant association between the number of hours worked per week and CMD. Spurgeon et al., (1997) suggested that those who work over 50 hours per week would be at greater risk of CMD. In addition Virtanen et al., (2011) indicated that individuals who work over 55 hours per week were more likely to be at risk of CMD than those who work 35-40 hours. However, greater hours can be assumed to indicate greater income and this may be considered to reduce the risk of CMD as there is reduced financial pressure. Greater hours may also indicate greater choice over the length of the working day in non-manual occupations. In accordance with this, Singh-Manoux et al., (2003) also indicate that household income and feeling financially secure is associated with health as they are aspects of social status.

Individuals who work long hours may enjoy doing so and it may provide meaning to life (Taylor, 2002). Similarly Bedeian et al., (1988) advocated that work may be central to individuals' lives as it is rewarding not only financially but also socially and emotionally. 
Equally Greenhaus and Powell (2006) suggest that work aspects and family aspects have additive effects on wellbeing. Barnett and Hyde (2001) propose that multiple roles are not harmful and are generally beneficial for both males and females in terms of mental health. This may be because involvement in both work and family roles may provide compensatory satisfaction from conflict in one of the other roles (Greenhaus \& Powell, 2006).

As well as work-life conflict other forms of job demands were assessed, namely mental and emotional demands at work. The association between CMD and mental and emotional demands became significant after adjustment for gender, marital status, social class and qualifications. This association may be dependent on the nature of the work as those who were in social class III manual were less likely to experience work-family conflict than those who were in social class III non-manual. This may be because many social class III manual jobs are associated with low psychological strain as individuals may be self-employed and have greater control over their jobs (Stansfeld \& Candy, 2006).

\section{Strengths and limitations}

This study has a number of limitations. Work-life conflict was assessed using a single item and this would be better assessed through a multi-item questionnaire (Carlson, Kacmar \& Williams, 2000). There are a number of questionnaires that deal with work-life conflict in more detail - the use of one of these would have given a more reliable measure of work-family conflict. The item available to us did not fully capture the three aspects of work-life conflict: time-based, strain-based and behaviour-based conflict (Carlson et al, 2000). The generalisability of the 1958 British birth cohort to the wider population must also be considered. These analyses are of cohort members at 45 years old. This may be a late stage in life for work-family conflict, which may be more acute when for caring for younger dependent children (Shimazu et al., 2010; Seto et al., 2004). Thus our findings may not apply across time periods or to other age groups as people face different issues at different career stages (Bedeian et al., 1988).

Equally attrition needs to be taken into account. Although Atherton, Fuller, Shepherd, Strachan and Power (2008) advocate that the 1958 sample is broadly representative, they suggest there was underrepresentation of some groups: individuals who were psychologically distressed and individuals in lower social classes were prone to loss from the cohort. Consequently increased associations may be observed in the general population. Different associations with work-family conflict may also be observed for anxiety, depression and phobias, but this study did not have the statistical power to analyse associations for the different disorders.

These initial analyses could be refined by further work in a number of ways. Multiple imputation techniques could be used to address missing data. In longitudinal studies it is appropriate to take account of the time varying nature of social class and marital status and multiple waves of data would allow this. It would have been ideal to adjust our analyses for common mental disorders at 42 years (baseline) or to restrict the sample to those without common mental disorders at baseline. Unfortunately, there was no comparable measure of common mental disorder at age 42 years.

In spite of these limitations, studies of this nature allow us to begin to understand the potential causal links between mental health, work-family conflict, working hours and family structure. This study is one of few which examine temporal relationships between common mental disorders and work-life conflict.

\section{Clinical and public health implications}

These findings are pertinent as the balance between work and life is considered to be an important current focus in Britain (Taylor, 2002). Common mental disorders are the second most significant cause of sickness absence from work for longer than 21 days (Nieuwenhujisen, Verbeek, deBoer, Blonk, \& van Dijk, 2006). As a result work-life policies have been implemented (Wheatley, 2012) which may benefit from further understanding of which factors increase risk of common mental disorders. Work-family conflict was found to be a significant risk factor for CMD. Although work hours did not directly impact the prevalence of CMD they had a significant impact on work-family conflict, which has not been seen in previous studies.

\section{Future research}

Further studies are required in order to assess work-family balance as a whole as family-work conflict was not assessed (Byron, 2005). Additionally further research could include more on family structure and socioeconomic status, such as total household income, in order to formulate a more complete understanding of the factors that contribute to the prevalence of common mental 
disorders within the family. Moreover, further analyses examining work-family conflict and common mental disorders may be studied by occupation in order to understand whether associations differ by occupation as they do by social class. Similarly, additional analyses exploring gender differences may be beneficial. Moreover, to take full advantage of the richness of multiple waves of data available in the cohort it would be useful to carry out structural equation modelling of the predictors of work-family conflict and their antecedents.

\section{Conclusions}

In conclusion, work-family conflict was a significant longitudinal predictor for common mental disorders. The number of hours worked was not associated with the prevalence of CMD, though increased work hours are associated with less workfamily conflict. Furthermore, working overtime was associated with reduced risk of work-family conflict. The findings suggest that reducing the work-family conflict that individuals face may reduce the risk of CMD. Further research into factors that cause workfamily conflict is required.

\section{Acknowledgements}

These analyses were carried out as part of an undergraduate dissertation; no additional funding was required. We thank the data providers: Centre for Longitudinal Studies, Institute of Education and National Birthday Trust Fund, National Children's Bureau, City University Social Statistics Research Unit (original data producers).

\section{References}

Adler, N. E., \& Ostrove, J. M. (1999). Socioeconomic status and health: what we know and what we don't. Annals of the New York Academy of Sciences, 896, 3-15. http://dx.doi.org/10.1111/j.1749-6632.1999.tb08101.x

Atherton, K., Fuller, E., Shepherd, P., Strachan, D. P., \& Power, C. (2008). Loss and representativeness in a biomedical survey at age 45 years: 1958 British birth cohort. Journal of Epidemiology and Community Health, 62, 216-223. http://dx.doi.org/10.1136/jech.2006.058966

Barnett, R. C., \& Hyde, J. S. (2001). Women, men, work, and family. American Psychologist, 56, 781-796. http://dx.doi.org/10.1037/0003-066X.56.10.781

Bebbington, P. (1987). Marital status and depression: a study of English national admission statistics. Acta Psychiatrica Scandinavica, 75, 640-650. http://dx.doi.org/10.1111/j.1600-0447.1987.tb02849.x

Bedeian, A. G., Burke, B. G., \& Moffett, R. G. (1988). Outcomes of work-family conflict among married male and female professionals. Journal of Management, 14, 475-491. http://dx.doi.org/10.1177/014920638801400310

Byron, K. (2005). A meta-analytic review of work-family conflict and its antecedents. Journal of Vocational Behavior, 67, 169-198. http://dx.doi.org/10.1016/j.jvb.2004.08.009

Canivet, C., Östergren, P. O., Lindeberg, S. I., Choi, B., Karasek, R., Moghaddassi, M., \& Isacsson, S. O. (2010). Conflict between the work and family domains and exhaustion among vocationally active men and women. Social Science \& Medicine, 70, 1237-1245. http://dx.doi.org/10.1016/j.socscimed.2009.12.029

Carlson, D.S., Kacmar, K.M., Williams LJ. (2000). Construction and initial validation of a multidimensional measure of work-family conflict. Journal of Vocational Behavior, 56, 249-276. http://dx.doi.org/10.1006/jvbe.1999.1713

Casper, W. J., Eby, L. T., Bordeaux, C., Lockwood, A., \& Lambert, D. (2007). A review of research methods in IO/OB work-family research. Journal of Applied Psychology, 92, 28-43. 
http://dx.doi.org/10.1037/0021-9010.92.1.28

Cinamon, R. G., \& Rich, Y. (2002). Gender differences in the importance of work and family roles: Implications for work-family conflict. Sex Roles, 47, 531-541. http://dx.doi.org/10.1023/A:1022021804846

Clark, C., Pike, C., McManus, S., Harris, J., Bebbington, P., Brugha, T. Jenkins, R., Meltzer, H., Weich, S., \& Stansfeld, S. (2011). The contribution of work and non-work stressors to common mental disorders in the 2007 Adult Psychiatric Morbidity Survey. Psychological Medicine, 1, 1-14.

Clark, C., Rodgers, B., Caldwell, T., Power, C., \& Stansfeld, S. (2007). Childhood and adulthood psychological ill health as predictors of midlife affective and anxiety disorders: the 1958 British Birth Cohort. Archives of General Psychiatry, 64, 668-678. http://dx.doi.org/10.1001/archpsyc.64.6.668

Duxbury, L. E., \& Higgins, C. A. (1991). Gender differences in work-family conflict. Journal of Applied Psychology, 76, 60-73. http://dx.doi.org/10.1037/0021-9010.76.1.60

Duxbury, L., Higgins, C., \& Lee, C. (1994). Work-Family Conflict A Comparison by Gender, Family Type, and Perceived Control. Journal of Family Issues, 15, 449-466. http://dx.doi.org/10.1177/019251394015003006

Frone, M. R. (2000). Work-family conflict and employee psychiatric disorders: The national comorbidity survey. Journal of Applied Psychology, 85, 888-895. http://dx.doi.org/10.1037/0021-9010.85.6.888

Frone, M. R., Russell, M., \& Cooper, M. L. (1992). Antecedents and outcomes of work-family conflict: testing a model of the work-family interface. Journal of Applied Psychology, 77, 133-161.

Frone, M. R., Russell, M., \& Cooper, M. L. (1997). Relation of work-family conflict to health outcomes: a fouryear longitudinal study of employed parents. Journal of Occupational and Organizational Psychology, 70, 325-335. http://dx.doi.org/10.1037/0021-9010.77.1.65

Fu, C. K., \& Shaffer, M. A. (2001). The tug of work and family: Direct and indirect domain-specific determinants of work-family conflict. Personnel Review, 30, 502-522. http://dx.doi.org/10.1108/EUM0000000005936

Grant-Vallone, E. J., \& Ensher, E. A. (2001). An examination of work and personal life conflict, organizational support, and employee health among international expatriates. International Journal of Intercultural Relations, 25, 261-278. http://dx.doi.org/10.1016/S0147-1767(01)00003-7

Greenhaus, J. H., \& Parasuraman, S. (1999). Research on work, family, and gender: Current status and future directions. In G. N. Powell (Ed.), Handbook of gender \& work, 391-412. Thousand Oaks, CA: Sage. http://dx.doi.org/10.4135/9781452231365.n20

Greenhaus, J. H., \& Powell, G. N. (2006). When work and family are allies: A theory of work-family enrichment. Academy of Management Review, 31, 72-92. http://dx.doi.org/10.5465/AMR.2006.19379625

Grzywacz, J. G., \& Bass, B. L. (2003). Work, Family, and Mental Health: Testing Different Models of WorkFamily Fit. Journal of Marriage and Family, 65, 248-261. http://dx.doi.org/10.1111/j.1741-3737.2003.00248.x

Guest, D. E. (2002). Perspectives on the study of work-life balance. Social Science Information, 41, 255-279. http://dx.doi.org/10.1177/0539018402041002005

Hämmig, O., \& Bauer, G. (2009). Work-life imbalance and mental health among male and female employees in Switzerland. International Journal of Public Health, 54, 88-95. http://dx.doi.org/10.1007/s00038-009-8031-7

Hämmig, O., Gutzwiller, F., \& Bauer, G. (2009). Work-life conflict and associations with work-and nonworkrelated factors and with physical and mental health outcomes: a nationally representative crosssectional study in Switzerland. BMC Public Health, 9, 435. http://dx.doi.org/10.1186/1471-2458-9-435 
Harrington, J. M. (2001). Health effects of shift work and extended hours of work. Occupational and Environmental Medicine, 58, 68-72.

http://dx.doi.org/10.1136/oem.58.1.68

Hemingway, H., Nicholson, A., Stafford, M., Roberts, R., \& Marmot, M. (1997). The impact of socioeconomic status on health functioning as assessed by the SF-36 questionnaire: the Whitehall II Study. American Journal of Public Health, 87, 1484-1490.

http://dx.doi.org/10.2105/AJPH.87.9.1484

Janzen, B. L., \& Kelly, I. W. (2012). Psychological Distress Among Employed Fathers Associations With Family Structure, Work Quality, and the Work-Family Interface. American Journal of Men's Health, 6, 294302.

http://dx.doi.org/10.1177/1557988311435835

Kendler, K. S., Prescott, C. A., Myers, J., \& Neale, M. C. (2003). The structure of genetic and environmental risk factors for common psychiatric and substance use disorders in men and women. Archives of General Psychiatry, 60, 929-937. http://dx.doi.org/10.1001/archpsyc.60.9.929

Lewis G, Pelosi AJ, Araya R, \& Dunn G. (1992). Measuring psychiatric disorder in the community: a standardized assessment for use by lay interviewers. Psychological Medicine, 22, 465-86. http://dx.doi.org/10.1017/S0033291700030415

Lewis, S. (2003). The integration of paid work and the rest of life. Is post-industrial work the new leisure? Leisure Studies, 22, 343-345. http://dx.doi.org/10.1080/02614360310001594131

Lorant, V., Deliège, D., Eaton, W., Robert, A., Philippot, P., \& Ansseau, M. (2003). Socioeconomic inequalities in depression: a meta-analysis. American Journal of Epidemiology, 157, 98-112. http://dx.doi.org/10.1093/aje/kwf182

Lowry, D., \& Moskos, M. (2008). Mobile phones, spillover and the 'work-life balance'. Mobility and Technology in the Workplace, 167-179.

Martens, M. F. J., Nijhuis, F. J. N., Van Boxtel, M. P. J., \& Knottnerus, J. A. (1999). Flexible work schedules and mental and physical health. A study of a working population with non-traditional working hours. Journal of Organizational Behavior, 20, 35-46. http://dx.doi.org/10.1002/(SICI)1099-1379(199901)20:1<35::AID-JOB879>3.0.CO;2-Z

Nieuwenhuijsen, K., Verbeek, J. H., de Boer, A. G., Blonk, R. W., \& van Dijk, F. J. (2006). Predicting the duration of sickness absence for patients with common mental disorders in occupational health care. Scandinavian Journal of Work, Environment \& Health, 67-74. http://dx.doi.org/10.5271/sjweh.978

Nitzsche, A., Jung, J., Pfaff, H., \& Driller, E. (2012). Employees' negative and positive work-home interaction and their association with depressive symptoms. American Journal of Industrial Medicine, 1-8.

Obidoa, C., Reeves, D., Warren, N., Reisine, S., \& Cherniack, M. (2011). Depression and work family conflict among corrections officers. Journal of Occupational and Environmental Medicine, 53, 1294-1301. http://dx.doi.org/10.1097/JOM.0b013e3182307888

Parsons, T. J., Power, C., \& Manor, O. (2001). Fetal and early life growth and body mass index from birth to early adulthood in 1958 British cohort: longitudinal study. British Medical Journal, 323, 1331-1335. http://dx.doi.org/10.1136/bmj.323.7325.1331

Power, C., \& Elliott, J. (2006). Cohort profile: 1958 British birth cohort (national child development study). International Journal of Epidemiology, 35, 34-41. http://dx.doi.org/10.1093/ije/dyi183

Power, C., Hertzman, C., Matthews, S., \& Manor, O. (1997). Social differences in health: life-cycle effects between ages 23 and 33 in the 1958 British birth cohort. American Journal of Public Health, 87, 1499-1503.

http://dx.doi.org/10.2105/AJPH.87.9.1499

Reynolds, J. (2005). In the Face of Conflict: Work-Life Conflict and Desired Work Hour Adjustments. Journal of Marriage and Family, 67, 1313-1331. 
http://dx.doi.org/10.1111/j.1741-3737.2005.00219.x

Seto, M., Morimoto, K., \& Maruyama, S. (2004). Effects of work-related factors and work-family conflict on depression among Japanese working women living with young children. Environmental Health and Preventive Medicine, 9, 220-227.

http://dx.doi.org/10.1007/BF02898103

Shimazu, A., Bakker, A. B., Demerouti, E., \& Peeters, M. C. (2010). Work-family conflict in Japan: how job and home demands affect psychological distress. Industrial Health, 48, 766-774.

http://dx.doi.org/10.2486/indhealth.MS1131

Simon, R. W. (2002). Revisiting the Relationships among Gender, Marital Status, and Mental Health.

American Journal of Sociology, 107, 1065-1096.

http://dx.doi.org/10.1086/339225

Singh-Manoux, A., Adler, N. E., \& Marmot, M. G. (2003). Subjective social status: its determinants and its association with measures of ill-health in the Whitehall II study. Social Science \&Medicine, 56, 13211333. http://dx.doi.org/10.1016/s0277-9536(02)00131-4

Spurgeon, A., Harrington, J. M., \& Cooper, C. L. (1997). Health and safety problems associated with long working hours: a review of the current position. Occupational and Environmental Medicine, 54, 367375. http://dx.doi.org/10.1136/oem.54.6.367

Stansfeld, S. A., Clark, C., Rodgers, B., Caldwell, T., \& Power, C. (2008). Childhood and adulthood socioeconomic position and midlife depressive and anxiety disorders. The British Journal of Psychiatry, 192, 152-153. http://dx.doi.org/10.1192/bjp.bp.107.043208

Stansfeld, S., \& Candy, B. (2006). Psychosocial work environment and mental health-a meta-analytic review. Scandinavian Journal of Work, Environment \& Health, 443-462. http://dx.doi.org/10.5271/sjweh.1050

Takeuchi, T., \& Yamazaki, Y. (2010). Relationship between work-family conflict and a sense of coherence among Japanese registered nurses. Japan Journal of Nursing Science, 7, 158-168. http://dx.doi.org/10.1111/j.1742-7924.2010.00154.x

Taylor, R. (2002). The future of work-life balance. Economic and Social Research Council.

Virtanen, M., Ferrie, J. E., Singh-Manoux, A., Shipley, M. J., Stansfeld, S. A., Marmot, M. G., \& Kivimäki, M. (2011). Long working hours and symptoms of anxiety and depression: a 5-year follow-up of the Whitehall II study. Psychological Medicine, 41, 2485-2494. http://dx.doi.org/10.1017/S0033291711000171

Wang, J. L., Lesage, A., Schmitz, N., \& Drapeau, A. (2006). The relationship between work stress and mental disorders in men and women: findings from a population-based study. Journal of Epidemiology and Community Health, 62, 42-47. http://dx.doi.org/10.1136/jech.2006.050591

Weich, S., \& Lewis, G. (1998). Poverty, unemployment, and common mental disorders: population based cohort study. British Medical Journal, 317, 115-119. http://dx.doi.org/10.1136/bmj.317.7151.115

Wheatley, D. (2012). Work-life balance, travel-to-work, and the dual career household. Personnel Review, 41, $813-831$.

http://dx.doi.org/10.1108/00483481211263764 